\title{
Layers within layers: quantifying seasonal versus event processes in Arctic clastic varved sediments
}

Scott F. Lamoureux ${ }^{1}$ and Pierre Francus ${ }^{2}$

Advances in the interpretation of Arctic clastic varved sediments have emerged from long-term process monitoring, and micro-sedimentological and micro-geochemical analyses. These developments permit the identification and interpretation of the quantitative processes that form varves and allow novel paleoclimate records to be generated.

Clastic annually laminated (varved) lake sediments are important paleo-records from Arctic regions. They offer high temporal resolution where other natural archives are localized (ice cores) or unavailable (tree rings), and substantially contribute to regional paleoclimate syntheses (Kaufman et al. 2009). Clastic varves are composed of mineral material introduced to the lake by streams and rivers. The climate signal is conveyed through the generation of runoff and downstream sediment transport into the lake. Since the pioneering work of Hardy et al. (1996), who conducted field process studies in Arctic Canada to determine a quantitative relationship between climate, hydrology, sediment transport and varve deposition, a number of sedimentary studies have refined our understanding of the control mechanisms over sediment delivery to lakes and the type of paleoenvironmental information contained within clastic varves.

\section{Hydroclimate controls over} sediment transport

A key limitation to most field process studies has been their short-term nature of often only 2-3 years. Sustained monitoring efforts have emerged during the past decade, particularly the Cape Bounty Arctic Watershed Observatory (CBAWO; http://geog.queensu.ca/ cbawo) in the Canadian High Arctic. This project, initiated in 2003, develops long-term climate, hydrological and sediment datasets to investigate the processes that contribute to the formation of clastic varves and their paleoclimate record.

The work of Hardy et al. (1996) established a quantitative process relationship between upper air temperatures, discharge, and suspended sediment transport at Lake C2 on northern Ellesmere Island. Based on this relationship, meteorological data from the nearest long-term weather station were used to estimate total suspended sediment transport for the years 1950-1992. These estimates were then compared to the varve thickness record. Results showed strong similarity between the varve record and the modeled results, suggesting that the varve thickness was primarily controlled by summer air temperatures.

However, longer studies at CBAWO and elsewhere have shown limitations to the temperature-runoff relationship. For example in spring, the snowpack becomes exhausted as the season progresses with the result being that sediment transport is controlled at the seasonal scale by the quantity of available snow (Cockburn and Lamoureux 2008). While the melting snow in the catchment controls the total runoff and sediment transport during the

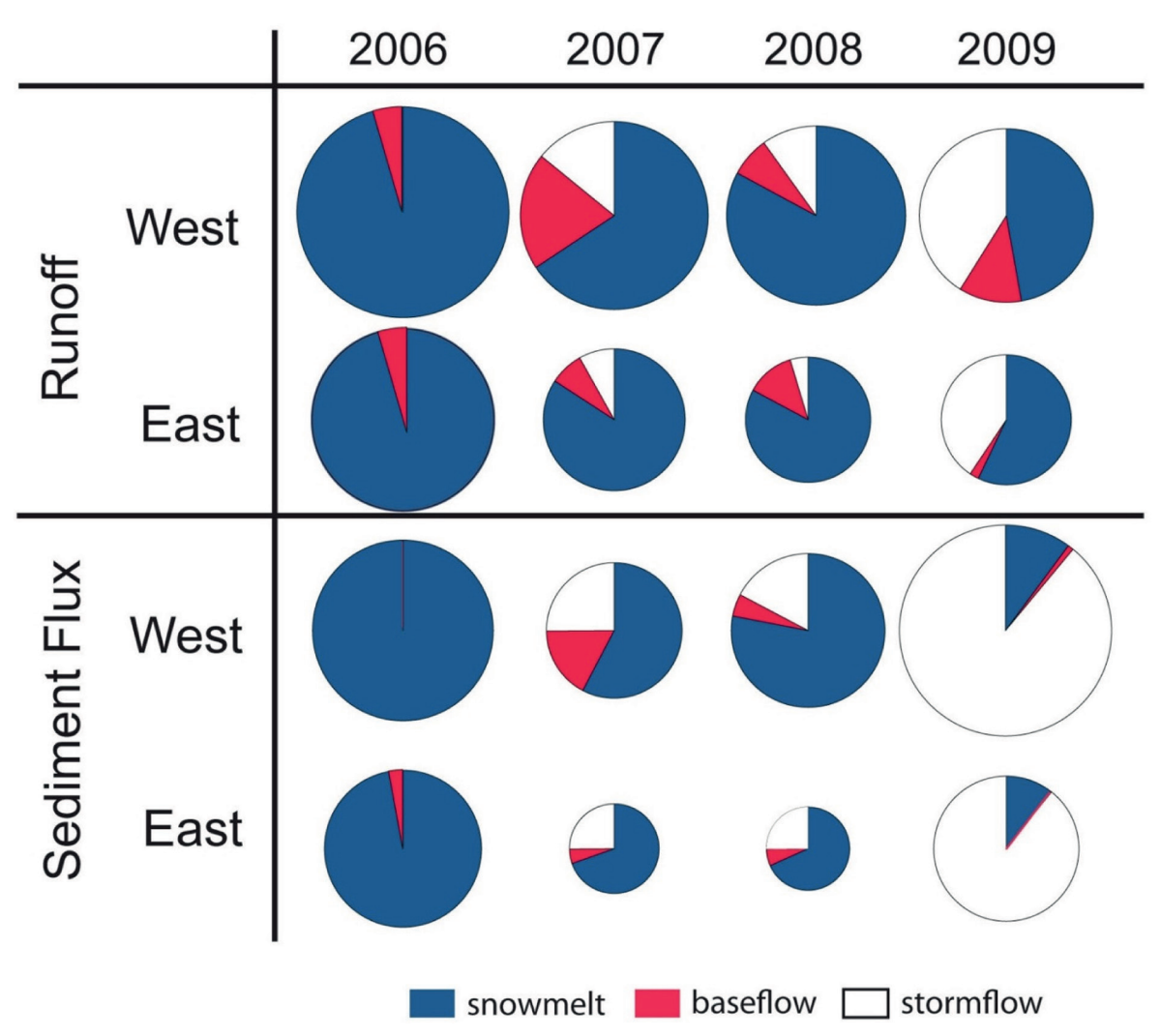

Figure 1: Four years of river discharge and suspended sediment flux at Cape Bounty Arctic Watershed Observatory (CBAWO). Pie size is scaled to the magnitude of flux. Note the contrast between 2006 when snowmelt dominated runoff and sediment transport, compared to 2009 when two major rainfall events were responsible for $89 \%$ of sediment transport (after Lewis et al. 2012). 


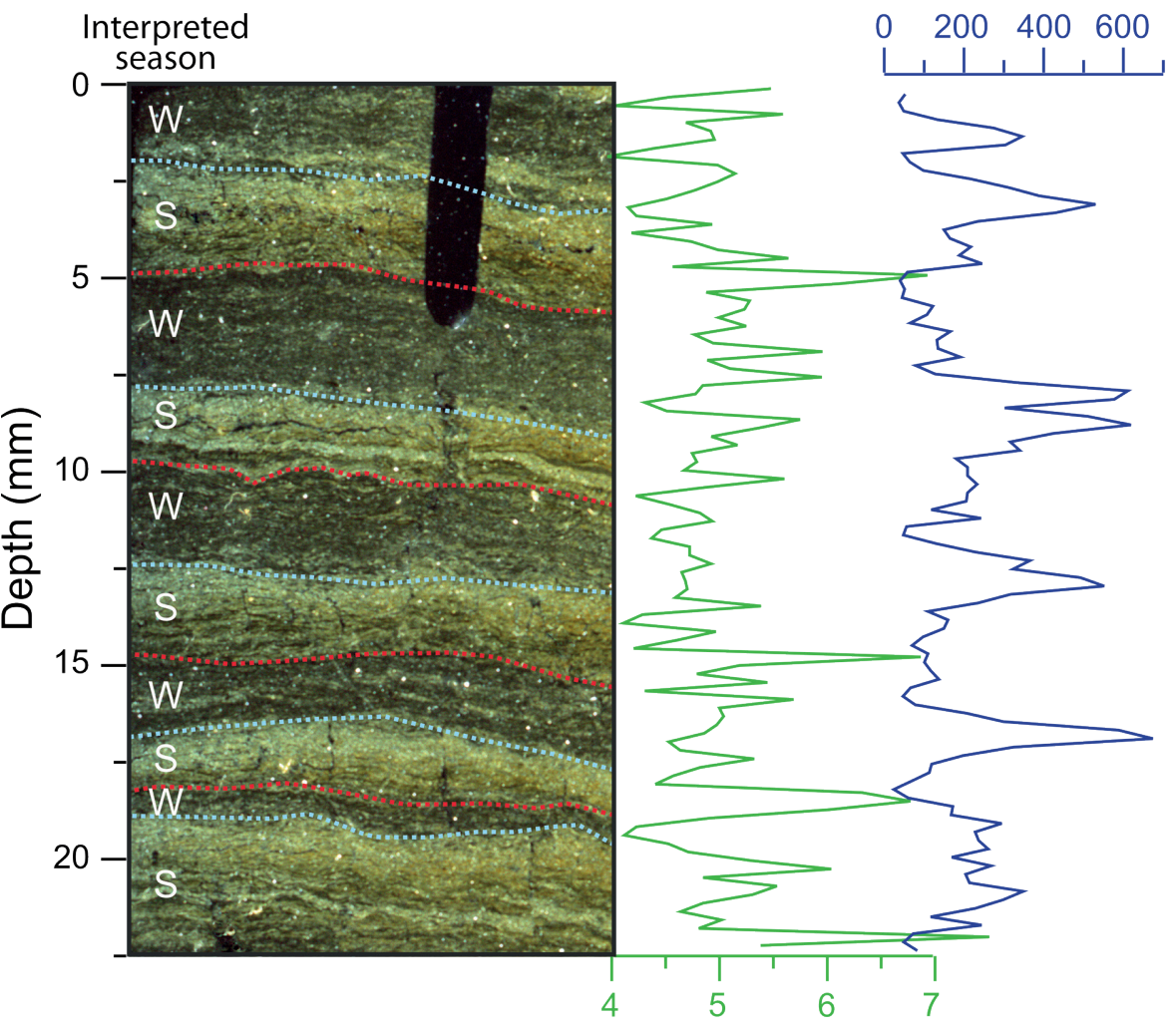

Equivalent disc diameter

$(\mu \mathrm{m})$

Figure 2: Results of an image analysis of particles in five varves from marine sediments in Saanich Inlet, British Columbia. This image was obtained using a flatbed scanner under cross-polarized light while particle size analysis was carried out at $220 \mu \mathrm{m}$ intervals (102 measurements in total). Interpreted seasons are indicated as winter (W) and summer (S) (Lewis et al. 2010). Blue dashed lines indicate the transition from underlying terrigenous sediment to overlying biogenic sediment and red lines indicate the opposite transition.

spring freshet, few studies have been able to assess the role of major rainfall on sediment transport and varve formation. Some studies in northwestern North America (Cockburn and Lamoureux 2007) and the Arctic (Francus et al. 2002; Chutko and Lamoureux 2008) have suggested rainfall only plays an intermittent role in the formation of clastic varves, but these studies depend on statistical assessment of the varve and related meteorological records, while direct rainfall and sediment transport data from the region were largely non-existent.

Therefore the long record from CBAWO provides valuable first systematic indications of the role of major rainfall events (although the likelihood of observing a rainfall event is low and unpredictable in the relatively dry High Arctic). Monitored rainfall events demonstrated that the sediment transport by a single rainfall event can equal, or exceed, that of the snow melt freshet (Lewis et al. 2012; Fig. 1). For example, a $35.7 \mathrm{~mm}$ rainfall event lasting several days in July 2009 transported $89 \%$ of the seasonal sediment flux, and would have presumably dominated the annual sedimentary structure. Analyses of smaller rainfall events from other years further suggest that the associated increase in runoff and sediment transport is non-linear (Lewis et al. 2012). For example, prior dry soil conditions can result in minimal discharge response and sediment transport. Hence, the sediment response to rainfall depends on both the amount and intensity of the rainfall, and the levels of soil moisture.

The results that have emerged from a decade of observation at CBAWO demonstrate the challenge of quantifying the role of rainfall in the process of varve formation; however, they also suggest that statistical associations of rainfall influence inferred from detailed sedimentology (Francus et al. 2002; Cockburn and Lamoureux 2007; Cuven et al. 2010; Lapointe et al. 2012) are highly plausible. Further refinement of these approaches is warranted, given the challenge of recognizing rainfall character from proxy evidence.

\section{Emergent analysis methods and new proxies}

There is a substantial need to systematically identify and determine operational proxies for interpreting long-term variations in finescale facies. The sedimentological analysis of varves has traditionally been done using thin sections, and the detailed study of intra-varve (or subannual) structures has been fruitful to identify single snowmelt and rainfall events (Cockburn and Lamoureux 2007; Chutko and Lamoureux 2008). Now, new techniques including micro $X$-ray fluorescence ( $\mu$-XRF) core scanning permit even more detailed characterization of subannual sedimentary structures, recognition of additional facies, and analysis of grain sizes (Cuven et al. 2010). Furthermore, semi-automated scanning electron microscopy acquisition and image analysis have made scanning of particle size structures possible even at (sub)annual resolution (Fig. 2). In a recent study, Lapointe et al. (2012) developed a 1750-year particle size distribution record from a High Arctic varve record, and through statistical analysis revealed significant relationships with summer rainfall. Hence, these new sedimentological approaches are providing the means to further discern the influence of rainfall and other climatic events on the sedimentary varve record in the Arctic and elsewhere.

\section{Future developments}

Recent work with Arctic varves has uncovered previously unrecognized hydroclimatic controls over sediment delivery to lakes, particularly the important, occasionally dominant, role of summer rainfall on sediment yield. Recognition of these hydroclimatic influences has been advanced through sustained field monitoring efforts, while new methodologies and an emphasis on fine-scale sediment facies analysis in clastic varves has yielded new proxy indicators and novel paleoclimate records. These substantial advances will help to improve the fidelity of paleoclimatic interpretations of Arctic varves and clastic varves in general. The next frontier will be the explicit combination of detailed facies analysis with proxy indicators (e.g. $\mu$-XRF geochemical data) and other novel sedimentological methods such as image analysis.

\section{ACKNOWLEDGEMENTS}

Funding has been provided by NSERC, the Canadian International Polar Year Program, and ArcticNet NCE, and field logistics by the Polar Continental Shelf Program.

\section{AFFILIATIONS}

'Department of Geography, Queen's University, Kingston, Canada

${ }^{2}$ Institut National de la Recherche Scientifique, Centre Eau Terre et Environnement, Québec, Canada

\section{CONTACT}

Scott F. Lamoureux: scott.lamoureux@queensu.ca

\section{SELECTED REFERENCES}

\section{Full reference list under:}

http://www.pages-igbp.org/products/newsletters/ ref2014_1.pdf

Chutko KJ, Lamoureux SF (2008) Can J Earth Sci 45: 1-13 Cockburn JMH, Lamoureux SF (2007) Quat Res 67: 193-203

Cuven S et al. (2010) J Paleolimnol 44: 803-817 Lapointe F et al. (2012) J Paleolimnol 48: 159-173 Lewis T et al. (2012) Hydrol Processes 26: 2003-2018 